\title{
Os (multi) letramentos e a interdisciplinaridade no ensino de Microbiologia
}

\author{
The (Multi) literacies and interdisciplinarity in the teaching of \\ Microbiology \\ Ricardo Ferreira Vale (falecomric@ hotmail.com) \\ Universidade Federal de Ouro Preto (UFOP) \\ Gracielle Teodora da Costa Pinto Coelho (gracielle.costa@unifemm.edu.br) \\ Centro Universitário de Sete Lagoas (Unifemm)
}

\author{
Marina Lanza Venuto (marivenuto37@gmail.com) \\ Secretaria Estadual de Educação de Minas Gerais (SEE/MG)
}

Resumo: Atualmente os (multi) letramentos e a interdisciplinaridade podem oferecer novos paradigmas para o processo de ensino/aprendizagem, que se sobrepõem às estruturas tradicionais de codificação e decodificação de conhecimentos. Este artigo tem como objetivo relatar uma experiência de trabalho, que contemplou diferentes ferramentas pedagógicas no ensino de microbiologia (fungos), aliando o ensino de Ciências da Natureza e Língua Portuguesa. Os percursos metodológicos foram constituídos nas seguintes etapas: a) aplicação de um questionário para verificação dos conhecimentos prévios dos alunos acerca da temática; b) apresentação de um livro paradidático; c) leitura coletiva da obra escolhida; d) solicitação de uma atividade prática; e) construção de um miniconto em parceria com a professora de Língua Portuguesa utilizando os apontamentos e fotografias produzidos pelos alunos na etapa anterior; f) transformação do miniconto e das imagens obtidas pelos alunos durante o processo de observação do experimento em vídeo; g) inserção do vídeo produzido pelos alunos na plataforma YouTube e h) aplicação de um novo questionário impresso objetivando verificar todo o processo de ensino/aprendizagem. Os resultados obtidos apontaram que a utilização de (multi) letramentos proporcionaram uma aprendizagem atrativa, estimulante e sobretudo significativa. Concluímos, assim, a importância de realizar um trabalho com inovadoras técnicas de ensino e interdisciplinaridade.

Palavras-chave: (Multi) letramentos; Recursos pedagógicos; Interdisciplinaridade; Ensino de microbiologia.

Abstract: Currently (multi) literacies and interdisciplinarity can offer new paradigms for the teaching / learning process, which overlap with traditional structures for encoding and decoding knowledge. This article aims to report a work experience, which included different pedagogical tools in the teaching of microbiology (fungi), combining the teaching of Natural Sciences and Portuguese Language. The methodological paths were constituted in the following stages: a) application of a questionnaire to verify the students' previous knowledge about the theme; b) presentation of a textbook; c) collective reading of the chosen work; d) requesting a practical activity; e) construction of a mini-story in partnership with the Portuguese language teacher using the notes and photographs produced by the students in the previous stage; f) transformation of the mini-story and the images obtained by the students during the process of observing the

Recebido em: 04/07/2020

Aceito em: $1 \% / 12 / 2020$ 
experiment on video; g) insertion of the video produced by the students on the Youtube platform and h) application of a new printed questionnaire to verify the entire teaching / learning process. The results obtained showed that the use of (multi) literacies provided an attractive, stimulating and above all significant learning. Therefore, we conclude the importance of carrying out work with innovative teaching and interdisciplinary techniques.

Keywords: (Multi) literacies; Pedagogical resources; Interdisciplinarity; Microbiology teaching.

\section{1. (Multi) letramentos: uma nova proposta de aprendizagem}

A distinção dos termos "letramento científico" e "alfabetização científica" tornouse expressivo nos meios acadêmicos da atualidade e, muitas vezes, são vistos como similares. Conforme Magda Soares (2000, p. 47) o termo "letramento" abrange "o estado ou condição de quem não sabe ler e escrever, mas cultiva as práticas sociais que usam a escrita" e o termo "alfabetização" é visto como "a ação de ensinar/aprender a ler e a escrever". Portanto, a ideia de "letramento científico" pode ser definida como aquela que contempla as vivências dos alunos e os novos conhecimentos adquiridos no espaço escolar. De acordo com Michelan e Andrade (2018, p. 23)

[...] o ensino de Ciências deve promover o letramento científico, que envolve a capacidade de compreender os fenômenos naturais e as relações entre os organismos, a natureza e a sociedade, de forma a ampliar esses conceitos na vida cotidiana. Além disso, o ensino de Ciências também deve estimular o desenvolvimento da autonomia dos alunos, fornecendo subsídios para que eles sejam capazes de tomar decisões e agir de forma consciente e responsável.

Podemos dizer que a "alfabetização científica" consiste em um processo no qual o aluno estabelece as competências de: leitura, entendimento e escrita de textos e de trabalhar com números e fórmulas. Segundo as reflexões de Rojo e Moura (2019, p. 12) acerca do processo de alfabetização

Esse processo não se resume apenas à aquisição dessas habilidades mecânicas (codificação e decodificação) do ato de ler, mas inclui a capacidade de interpretar, compreender, criticar, ressignificar e produzir conhecimento.

O processão de "alfabetização científica" viabiliza a socialização dos alunos com as múltiplas formas de interação e sua estrutura intrínseca de vivência. Com base nas informações relatadas corroboramos as ideias definidas pelo Grupo de Nova Londres ${ }^{1}$

\footnotetext{
${ }^{1}$ No final do século 20, em 1996, um grupo de pesquisadores ingleses, americanos e australianos reuniuse, na cidade de Nova Londres (EUA), para discutir as mudanças, então recentes, que estavam sofrendo os textos e, decorrentemente, os letramentos. Por isso, foi alcunhado como Grupo de Nova Londres
}

Recebido em: 04/07/2020

Aceito em: $1 \% / 12 / 2020$ 
(GNL), no que se refere às transformações sociais promovidas pela utilização de conhecimentos prévios que possibilitam nossas práticas sociais.

$\mathrm{O}$ aumento da diversidade cultural e linguística ocasionados pela globalização e explosão midiática (discutidos pelo GNL) impactou na ampliação dos "letramentos científicos" como nos diz Santos e Mortimer (2001, p. 96)

O letramento científico e tecnológico tornou-se, então, a principal meta do ensino de ciências, em contraste com os movimentos ocorridos nas décadas de 50 e 60, que eram centrados na preparação dos jovens para agirem na sociedade como cientistas ou optarem pela carreira científica. Nesse novo contexto, o letramento científico objetiva levar os alunos a compreenderem como C\&T [Ciência e Tecnologia) influenciam-se mutuamente; a tornaremse capazes de usar o conhecimento científico e tecnológico na solução de seus problemas no dia-a-dia; e a tomarem decisões com responsabilidade social

Diante desse novo contexto socioeconômico e cultural surge a "pedagogia dos (multi) letramentos científicos".

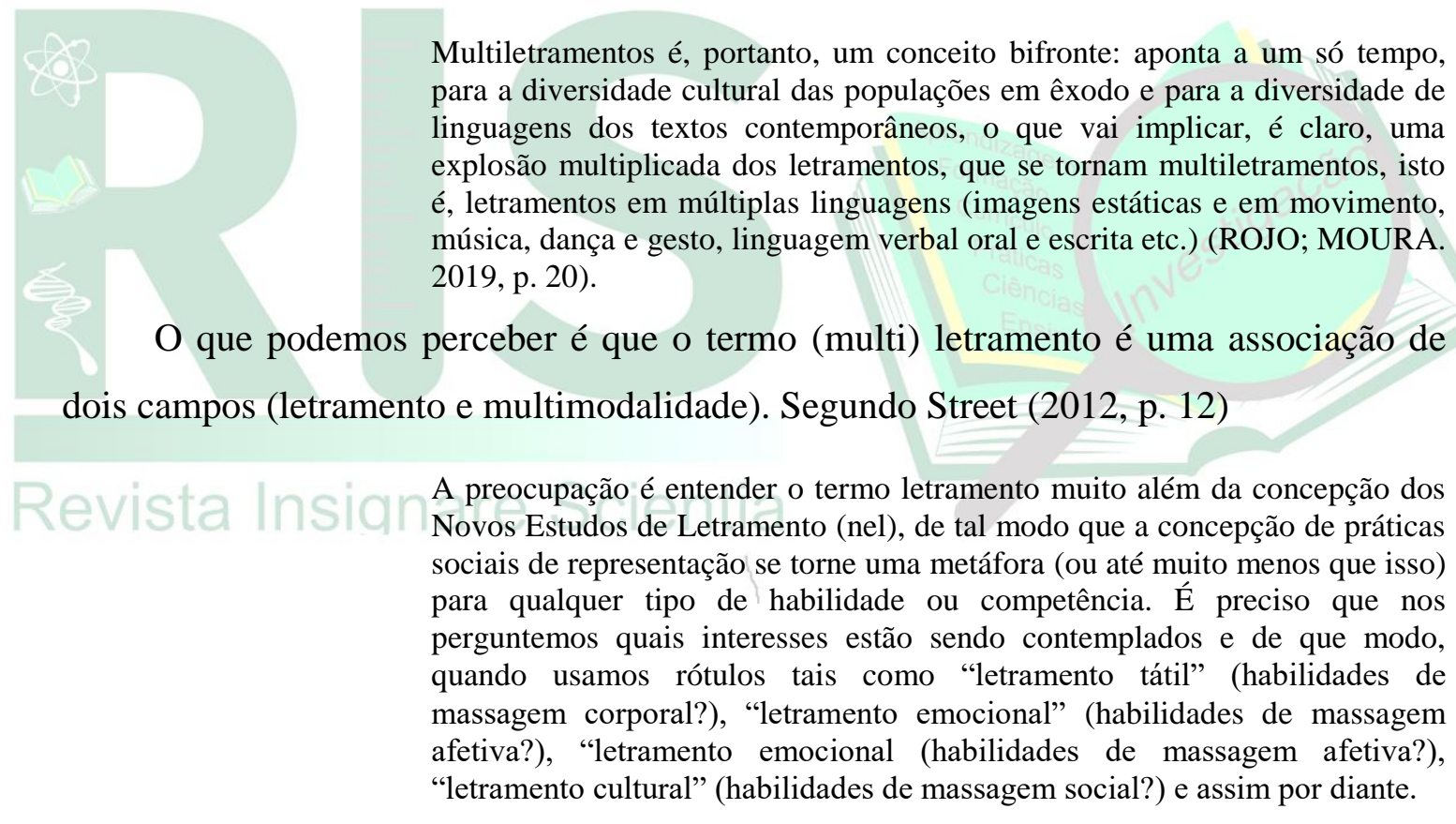

Portanto, concluímos que os (multi) letramentos abarcam novas realidades de leitura e escrita menos tradicionalistas e mais inovadoras, voltadas para a nova realidade que se apresenta.

\section{A BASE NACIONAL COMUM CURRICULAR E OS MULTI (LETRAMENTOS)}

(GNL- New London Group). Faziam parte do grupo pesquisadores como Bill Cope, Mary Kalantzis, Gunther Kress, James Paul Gee, Norman Fairclough, todos interessados em linguagem e educação linguística. (ROJO; MOURA. 2019, p. 19).

Recebido em: 04/07/2020

Aceito em: $1 \% / 12 / 2020$ 
A Base Nacional Comum Curricular (BNCC), homologada em 2017, é um documento proposto pelo Conselho Nacional de Educação que abrange todo o território brasileiro. Inicialmente, esse documento contempla o Ensino Infantil e o Ensino Fundamental.

As aprendizagens básicas determinadas na BNCC referem-se às habilidades e competências que se espera dos alunos na sua trajetória escolar. Todavia, as habilidades e competências não definem o currículo escolar que as escolas devem seguir, pois no Brasil permeia uma grande diversidade sociocultural e cada realidade requer um currículo específico. Arroyo é um dos autores que se preocupou com essa questão

Professores e educandos trazem às salas de aula suas experiências sociais, suas indagações desconcertantes sobre suas culturas, memórias e seus modos de viver, modos de pensar-se e pensar a sociedade, a cidade, o campo, suas vivências do tempo, do espaço, das lutas por sobreviver...Trazem os saberes de tantas resistências e ações por um digno e justo viver (ARROYO, 2013, p. 2).

Ressaltamos ainda que no Ensino Fundamental II a BNCC recomenda que os componentes curriculares resgatem, ressignifiquem e valorizem as aprendizagens contempladas no Ensino Fundamental I. Portanto, a educação deve promover uma interação crítica com variados gêneros de entendimento e de informação no processo de ensino/aprendizagem.

Concebemos que "Um dos desafios postos pela contemporaneidade é o de garantir, contextualizadamente, o direito humano universal, social inalienável à educação" (CRAVEIRO; MEDEIROS, 2013. p. 7). Ressaltamos também que a educação faz parte do ordenamento jurídico referente ao direito público subjetivo, ou seja, o direito substancial dos cidadãos de acesso ao ensino fundamental.

A articulação entre o processo de ensino/aprendizagem e os (multi) letramentos é contemplada na Competência Geral nº 04 da BNCC que enfatiza

Utilizar diferentes linguagens - verbal (oral ou visual-motora, como libras e escrita), corporal, visual, sonora e digital -, bem como conhecimentos das linguagens artística, matemática e científica, para se expressar e partilhar informações, experiências, ideias e sentimentos em diferentes contextos e produzir sentidos que levem ao entendimento mútuo.

Assim, concluímos que a aprendizagem pode ser concretizada através dos (multi) letramentos favorecendo a aproximação dos conceitos científicos experienciados pelos alunos.

\section{O ENSINO DE MICROBIOLOGIA}

Recebido em: 04/07/2020

Aceito em: $1 \% / 12 / 2020$ 
A invenção do microscópio favoreceu o estudo de seres muito pequenos (seres microscópicos) como as bactérias, os fungos, os protozoários e os vírus originando uma ciência - a microbiologia. Avila-Campos (2016, p. 1) define microbiologia como:

\begin{abstract}
A palavra Microbiologia deriva do grego: mikros ("pequeno"), bios (“vida"), e logos ("ciência"). Esta Ciência estuda os organismos microscópicos e suas atividades biológicas, isto é, verificam as diversas formas, estruturas, reprodução, aspectos bioquímico-fisiológicos, e seu relacionamento entre si e com o hospedeiro, podendo ser benéficos e prejudiciais. A Microbiologia trata os organismos microscópicos unicelulares, onde todos os processos vitais são realizados numa única célula.
\end{abstract}

A BNCC/2017 contempla o estudo de microbiologia no Ensino Fundamental II como pré-requisito para otimizar as habilidades EF07CI09 e EF07CI10 que tem como objeto de conhecimento: programas e indicadores de saúde pública. Dessa forma, o ensino de microbiologia deverá fornecer arcabouço científico para que os alunos possam compreender as situações de saúde da sociedade.

A articulação entre o conhecimento prévio do aluno e as práticas escolares será capaz de tornar a aprendizagem para além de um processo de decodificação. Dentro dessa análise corroboramos com Varela (2020, p. 3)

As características do mundo moderno requerem também uma educação científica precoce, para que os futuros cidadãos estejam preparados para viverem nele, assumindo-se como sujeitos participativos, críticos e informados na tomada das suas decisões.

No início de nosso trabalho observamos que as práticas pedagógicas, quando existentes, no ensino de microbiologia em sua maioria encontram-se embasadas quase em sua totalidade em atividades de aulas práticas como: cultura de bactéria e fungos em meio nutritivo, estudo do processo de fermentação com uso de fermento biológico (Saccharomyces cerevisiae) e a fermentação láctica (fabricação de iogurte natural).

Destaca-se a importância de que os professores de Ciências da Natureza criem novas estratégias para o ensino de microbiologia com objetivo de atender as novas demandas que se apresentam no contexto atual. Diante dessa perspectiva, os professores de Ciências da Natureza devem promover novas estratégias pedagógicas que contemplem os (multi) letramentos transformando o ensino de microbiologia em uma aprendizagem significativa. Segundo Vale $(1998$, p. 6) "o mundo e a sociedade são o grande laboratório de pesquisa".

\title{
4. PERCURSOS METODOLÓGICOS
}

Recebido em: 04/07/2020

Aceito em: $1 \% / 12 / 2020$ 
Escolhemos como tema para a realização de trabalho "os fungos". O público participante foram 51 alunos do $7^{\circ}$ ano do Ensino Fundamental II de uma escola da rede privada de ensino, localizada na cidade de Sete Lagoas -MG.

A atividade foi desenvolvida a partir de 8 etapas a saber:

$1^{\text {a }}$ etapa - aplicação de um questionário impresso acerca da temática fungos, no qual abordou-se conceitos básicos como:

a) Conhecimento ou não da existência dos fungos;

b) Características morfofisiológicas;

c) Incidência;

d) A utilização dos mesmos na alimentação humana e/ou animal;

e) A aplicação de fungos na indústria farmacológica.

$2^{\text {a }}$ etapa - apresentação do livro paradidático "Dudu e o professor Aspergilo", da autora Alane Beatriz Vermelho, que aborda conceitos básicos acerca da temática fungos de forma lúdica e inovadora. Segundo Souza (2013, p. 3) o livro paradidático "proporciona o desenvolvimento de um estudo baseado nos aspectos históricos, sociais e culturais que circundam o tema em estudo, levando tanto o corpo discente como docente a explorar uma realidade muitas vezes desconhecida".

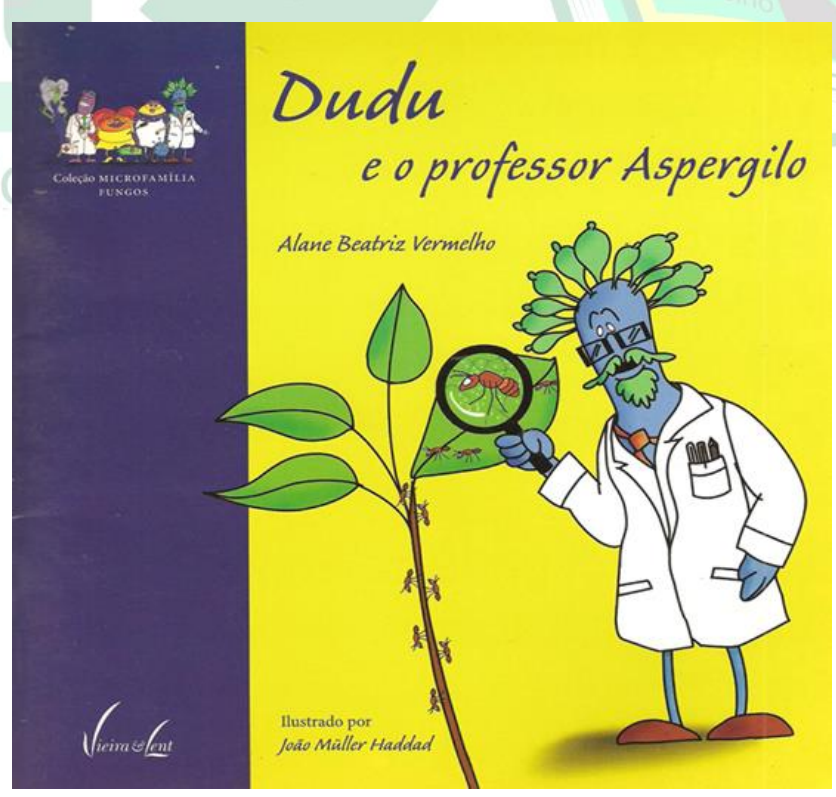

Figura 1- O livro paradidático selecionado "Dudu e o professor Aspergilo"

Fonte: Capa do livro "Dudu e o professor Aspergilo" Editora Vieira \& Lent, 2010

$3^{\text {a }}$ etapa - leitura coletiva da obra escolhida para o estudo da temática; 
$4^{\text {a }}$ etapa - solicitação de uma atividade prática (em casa), na qual os alunos deveriam observar durante 15 dias a incidência dos fungos em pães. Este experimento poderá proporcionar a observação de bolores, um fungo pluricelular (formado por mais de uma célula) que prolifera em lugares úmidos, escuros e pouco arejados. Para isso os alunos precisaram seguir os seguintes passos:

a) Pegar duas fatias de pão, umedecer apenas uma delas com spray de água e coloca-las em sacos plásticos distintos, identificando a fatia umedecida e a fatia seca. O objetivo foi formar uma camada fina do líquido sobre a massa, sem encharcar o pão. Uma única borrifada seria o suficiente para estimular o crescimento do mofo;

b) Em seguida, os alunos deveriam fechar os sacos onde os pães foram colocados até o fim do experimento, evitando a exposição com os esporos de bolor que iriam crescer no pão;

c) Então, os pães embalados foram colocados em local úmido e levemente aquecido.

Aponte a câmera seu celular para a figura 2 e assista de modo interativo o vídeo produzido pelos alunos, acerca da montagem do experimento de cultura de fungos em pães.

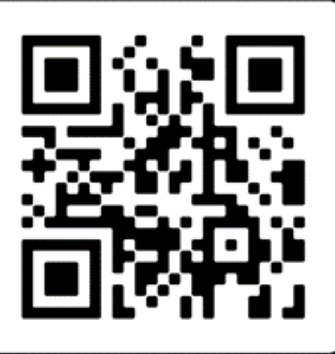

ASSISTA AGORA

Figura 2- $Q R \operatorname{code}^{2}$ com a montagem do experimento de cultura de fungos em pães

Fonte: VALE, Ricardo.Como cultivar fungos em sua casa. 2020

No decorrer do experimento os alunos fizeram apontamentos e fotografaram o fenômeno.

$5^{\text {a }}$ etapa - construção de um miniconto, em parceria com a professora de Língua Portuguesa, utilizando os apontamentos e fotografias produzidos na $4^{\mathrm{a}}$ etapa. De acordo

${ }^{2}$ O Quick Response (QR code) é um código de barras bidimensionais que pode ser escaneado pela maioria dos telefones celulares munidos de câmera. Esse código é transformado em um endereço de URL.

Recebido em: 04/07/2020

Aceito em: $1 \% / 12 / 2020$ 
Spalding (2008, p. 9) o miniconto é uma "estética própria da contemporaneidade e herdeiro do minimalismo". Corroborando com as ideias relatadas por Spalding (2008) Rojo e Moura (2012, p. 80) indicam que

$\mathrm{Na}$ contemporaneidade, com as tecnologias digitais, esse gênero tomou um novo fôlego, sendo amplamente publicado em blogs, celulares, Twitter, dentre outras ferramentas. Esse fôlego foi renovado devido à fluidez e à rapidez com que as informações são divulgadas por meios tecnológicos digitais que exigem outras formas de leitura, outros gêneros de textos e outros letramentos.

Por fim, salientamos que os usos da ferramenta pedagógica de construção dos minicontos pelos alunos poderão proporcionar uma ampla gama de conhecimentos não apenas no estudo de Ciências da Natureza, mas também em (multi) modalidades de escrita e letramento.

$6^{\text {a }}$ etapa - transformação do miniconto e das imagens obtidas pelos alunos durante o processo de observação do experimento, em vídeo com o uso das ferramentas Made with VideoShow, Made with Kinemaster e Windows movie maker.

$7^{\mathrm{a}}$ etapa - inserção do vídeo produzido pelos alunos na plataforma Youtube.

$8^{\text {a }}$ etapa - aplicação de um novo questionário impresso com o objetivo de verificar todo o processo de ensino/aprendizagem na construção das ferramentas propostas para o estudo da temática fungos e verificação dos conhecimentos agregados acerca da temática.

Quando sugerimos aos alunos uma atividade na qual eles próprios constroem seus instrumentos de estudo, estamos estimulando o seu protagonismo e valorizando as experiências prévias de aprendizagem. Desse modo, Stumpenhorst (2018, p. 47) nos diz que, "no entanto, se quisermos que os alunos continuem como aprendizes por toda a sua vida, temos que deixar que eles façam o aprendizado".

\section{RESULTADOS E DISCUSSÕES}

Após a realização das atividades propostas, colhemos como resultados as seguintes informações relatadas no QUADRO 1, abaixo:

Quadro 1 - Questionário para verificação dos conhecimentos prévios dos alunos acerca da temática fungos

\begin{tabular}{|l|c|c|}
\hline & Sim & Não \\
\hline Você sabe o que são os fungos? & 56,6 & 43,4 \\
\hline Todos os fungos são patogênicos? & 4,7 & 95,3 \\
\hline Existem fungos comestíveis? & 92,2 & 7,8 \\
\hline
\end{tabular}

Recebido em: 04/07/2020

Aceito em: $1 \% / 12 / 2020$ 


\begin{tabular}{|l|c|c|}
\hline Você sabe o que é queijo Camembert? & 58,5 & 41,5 \\
\hline $\begin{array}{l}\text { Você sabe o que é um micro- } \\
\text { organismo? }\end{array}$ & 100 & 0 \\
\hline Todo fungo é um micro-organismo? & 74,4 & 25,6 \\
\hline Você já ouviu o termo micrômetro? & 54,7 & 75,3 \\
\hline $\begin{array}{l}\text { Existem fungos que podem produzir } \\
\text { medicamentos que combatem } \\
\text { doenças? }\end{array}$ & 92,5 & 43,4 \\
\hline $\begin{array}{l}\text { Você sabe a diferença de um } \\
\text { microscópio ótico de um microscópio } \\
\text { eletrônico? }\end{array}$ & 56,6 & 94,3 \\
\hline $\begin{array}{l}\text { Os fungos são a mesma coisa do que } \\
\text { bactérias? }\end{array}$ & 5,5 & \\
\hline
\end{tabular}

Podemos perceber que, como conhecimento prévio, a maioria dos alunos já possuíam algum tipo de conhecimento acerca da existência dos fungos, de suas características morfosiológicas, de sua incidência, da utilização dos fungos na alimentação humana e/ ou animal e da aplicação dos mesmos na indústria farmacológica.

A utilização do livro paradidático proporcionou uma grande interação dos alunos acerca da temática fungos, por se tratar de uma obra atrativa que explorava além de uma leitura de fácil compreensão e assimilação de imagens envolventes e cativantes que exploravam a ludicidade do tema. Segundo Almeida, (2009, p. 1), "O lúdico faz parte das atividades essenciais da dinâmica humana, caracterizando-se por ser espontâneo, funcional e satisfatório".

Diante da atratividade proporcionada pelo livro paradidático "Dudu e o professor Aspergilo", os alunos se sentiram mais estimulados a realizarem a atividade prática no que tange a produção de fungos através de pães. Segundo Krasilchik (2008, p. 88) as aulas práticas "permitem que os alunos tenham contato direto com os fenômenos, manipulando os materiais e equipamentos e observando organismos".

Estimulados pela leitura, pelo experimento proposto e de posse de seus apontamentos e fotografias os alunos encontraram-se preparados para a produção do miniconto. Essas informações construídas pelos alunos foram aproveitadas pela professora de Língua Portuguesa para a elaboração do miniconto, de acordo com a estética linguística que ele propõe.

Ainda com a colaboração da professora de Língua Portuguesa o miniconto e as imagens obtidas pelos alunos durante o processo de experimentação foram transformadas em vídeo e inseridas na plataforma YouTube com grande entusiasmo. De acordo com Rojo e Moura (2012, p. 95), “Na contemporaneidade, as novas tecnologias 
Vol. 3, n. 5. Set./Dez.

ISSN: 2595- 4520

de informação e de comunicação - TICS - têm exigido práticas letradas que requerem um deslocamento das práticas canônicas realizadas pelos protagonistas do cenário das escolas. Segue abaixo o vídeo produzido pelos alunos.

Aponte a câmera do seu celular para as figuras 3 e 4 e assista de modo interativo o vídeo produzido pelos alunos, relatando seus apontamentos e fotografias em forma de um miniconto.

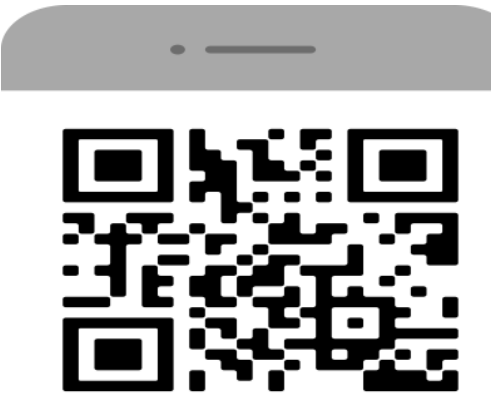

\section{ESCANEIE-ME}

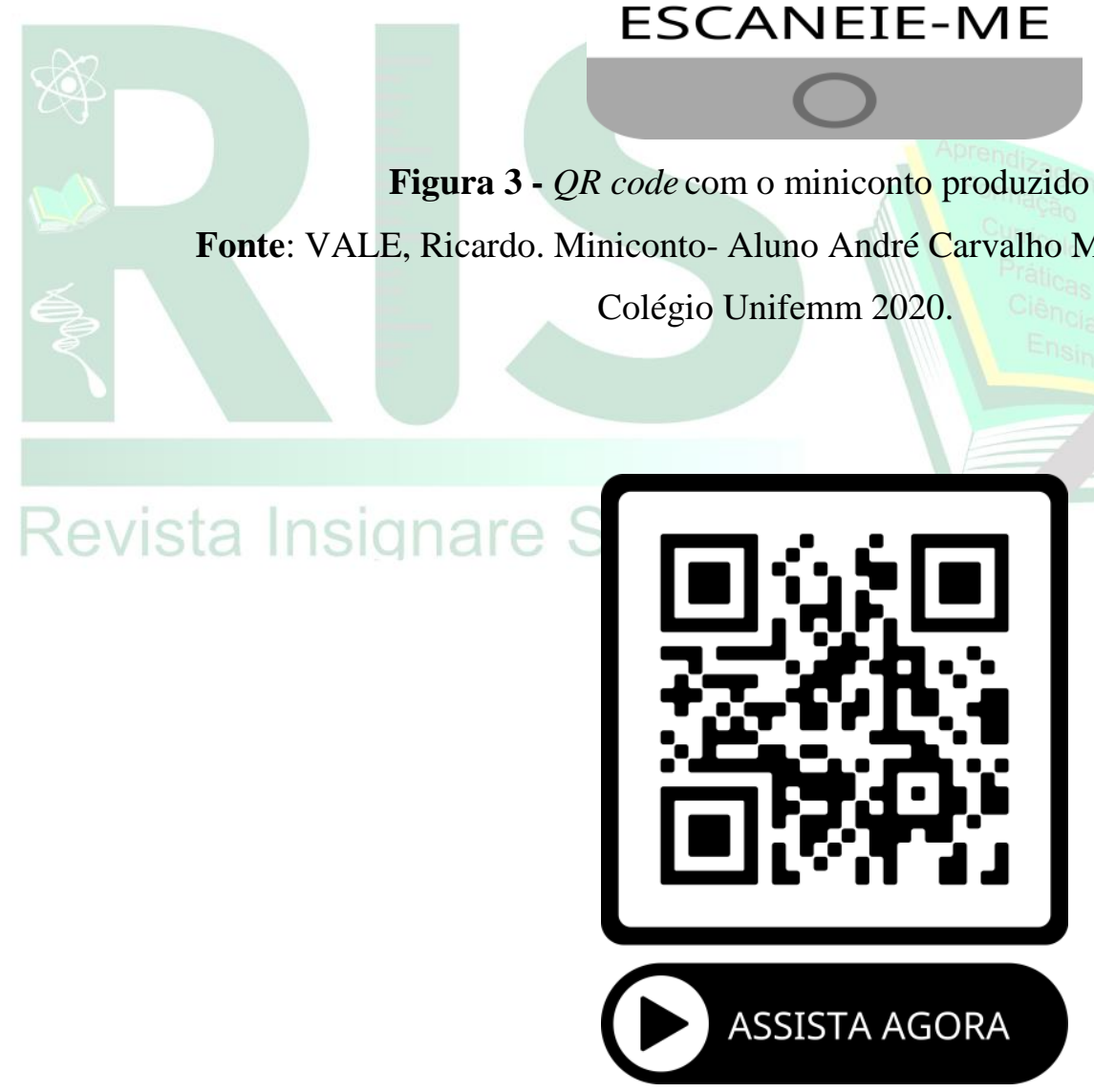

Figura 4 - $Q R$ code com o miniconto produzido pelos alunos

Fonte: VALE, Ricardo. Miniconto- Aluna Bárbara Rodrigues Oliveira- 7 B- Colégio Unifemm 2020. 
Vol. 3, n. 5. Set./Dez.

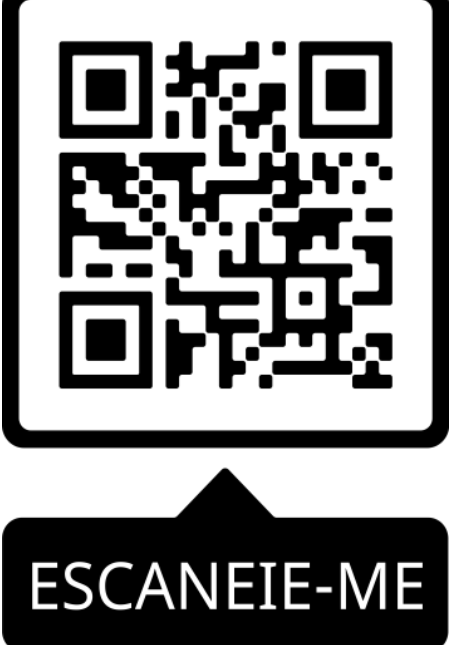

Figura 5 - $Q R$ code com o miniconto produzido pelos alunos

Fonte: VALE, Ricardo. Miniconto- Aluno Otávio- 7 B- Colégio Unifemm 2020.
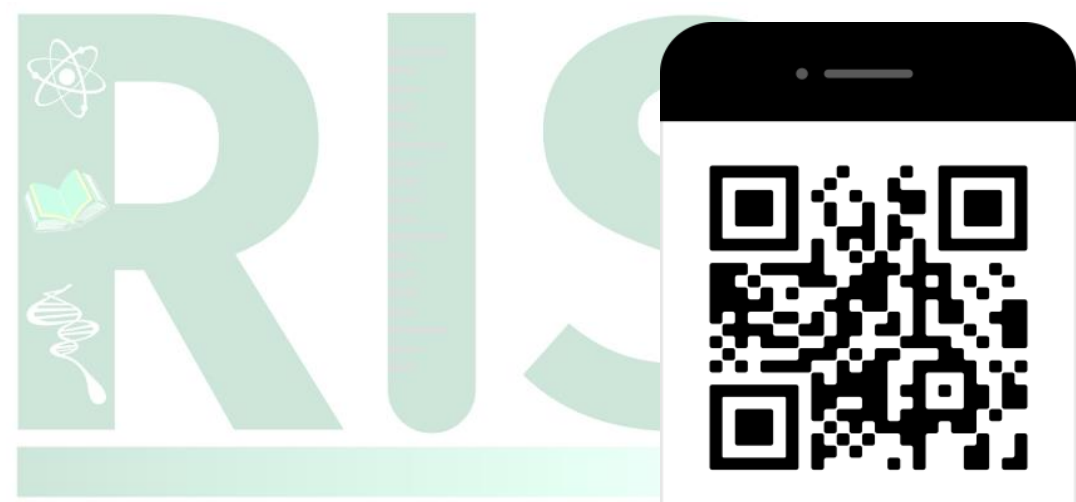

\section{ESCANEIE-ME}

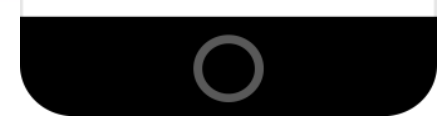

Figura 6 - $Q R$ code com o miniconto produzido pelos alunos

Fonte: VALE, Ricardo. Miniconto- Aluna Flávia Helena Ferreira- 7 ano B Colégio Unifemm 2020.

Após os processos relatados acima e de posse das informações oriundas do novo questionário aplicado percebemos como uma atividade inovadora e lúdica pode instigar os alunos a conhecerem mais a temática abordada e solidificarem seus conhecimentos acerca da mesma. No QUADRO 2, percebemos essa solidificação de conhecimentos.

Quadro 2 - Questionário para verificação dos conhecimentos adquiridos pelos alunos após a execução dos trabalhos propostos

\begin{tabular}{|l|c|c|}
\hline & Sim & Não \\
\hline Você sabe o que são fungos? & 83,7 & 16,3 \\
\hline
\end{tabular}




\begin{tabular}{|l|c|c|}
\hline Todos os fungos são patogênicos? & 0 & 100 \\
\hline Existem fungos comestíveis? & 97,7 & 2,3 \\
\hline Você sabe o que é queijo Camembert? & 86 & 14 \\
\hline $\begin{array}{l}\text { Você sabe o que é um micro- } \\
\text { organismo? }\end{array}$ & 100 & 0 \\
\hline Todo fungo é um micro-organismo? & 20,8 & 79,4 \\
\hline Você já ouviu o termo micrômetro? & 90,7 & 9,3 \\
\hline $\begin{array}{l}\text { Existem fungos que podem produzir } \\
\text { medicamentos que combatem } \\
\text { doenças? }\end{array}$ & 95,3 & 4,7 \\
\hline $\begin{array}{l}\text { Você sabe a diferença de um } \\
\text { microscópio ótico de um microscópio } \\
\text { eletrônico? }\end{array}$ & 86 & 14 \\
\hline $\begin{array}{l}\text { Os fungos são a mesma coisa do que } \\
\text { bactérias? }\end{array}$ & 4,7 & 95,3 \\
\hline
\end{tabular}

\section{CONSIDERAÇÕES FINAIS}

O uso de novas tecnologias no ensino de microbiologia tem se mostrado eficazes na promoção de (multi) letramentos para uma aprendizagem significativa. Diante do novo contexto sociocultural vivenciado no século XXI nas instituições de ensino tornase imprescindível a utilização de práticas pedagógicas capazes de inserir essa nova geração de alunos como protagonistas e construtores do seu próprio processo de ensino/aprendizagem. Como nos diz Pinheiro e Cardoso (2020, p. 58): "o mundo contemporâneo é mutável, especialmente no tocante as atividades diretamente ligadas aos processos científicos e tecnológicos".

As facilidades promovidas pelas novas tecnologias, disponíveis no ambiente virtual, podem se tornar ferramentas colaborativas dos professores por apresentarem opções para as práticas de (multi) letramentos.

Os trabalhos desenvolvidos junto aos alunos acerca da temática fungos mostraram-se eficazes no que se refere ao interesse e envolvimento dos mesmos quando estes perceberam que estavam produzindo os seus próprios instrumentos de estudo, bem como protagonizando o processo de ensino/aprendizagem.

Portanto, concluímos que os professores, se quiserem que os alunos aprendam e apreendam os conhecimentos de forma atrativa e significativa, devem buscar incansavelmente novas ferramentas de aprendizagem além da simples utilização de livros didáticos.

\section{REFERÊNCIAS}

Recebido em: 04/07/2020

Aceito em: $1 \% / 12 / 2020$ 
ALMEIDA, Anne. Recreação: ludicidade como instrumento pedagógico. Disponível em: https://www.cdof.com.br/recrea22.htm. Acesso em 15 jun. 2020.

ARROYO, Miguel G. Currículo, território em disputa. 5 ed. Petrópolis, RJ: Vozes, 2013.

AVILA-CAMPOS, Mário Júlio. Introdução à microbiologia. 2016. Disponível em: http://www.icb.usp.br/bmm/mariojac/arquivos/Aulas/Introducao_Microbiologia_Texto. pdf. Acesso em 27 mai. 2020.

BRASIL. Ministério da Educação e Cultura. Base Nacional Comum Curricular. Versão final. Brasília: MEC, 2017 p. 19. Disponível em: http://basenacionalcomum.mec.gov.br/images/BNCC_EI_EF_110518_versaofinal_site. pdf. Acesso em 23 mai. 2020.

CRAVEIRO, Clélia Brandão Alvarenga; MEDEIROS, Simone (Org.). Diretrizes Curriculares Nacional para a Educação Básica: diversidade e inclusão. Brasília: Conselho Nacional de Educação/Ministério da Educação, Secretaria de Educação Continuada, Alfabetização, Diversidade e Inclusão, 2013.

MICHELAN, Vanessa; ANDRADE, Elisangela. Convergências Ciências. 2 ed. São Paulo: SM, 2018.

KRASILCHIK, Myriam. Prática de ensino de Biologia. 4. ed. São Paulo: Edusp, 2008.

PINHEIRO, Adriana Ramos; CARDOSO, Sheila Pressentin. O lúdico no ensino de ciências: uma revisão na Revista Brasileira de Pesquisa em Educação em Ciências. Revista Insignare Scientia - RIS, v. 3, n. 1, p. 57-76, 4 jun. 2020.

ROJO, Roxane; MOURA, Eduardo. Letramentos, mídias, linguagens. São Paulo: Parábola Editorial, 2019.

ROJO, Roxane; MOURA, Eduardo. Multiletramentos na escola. São Paulo: Parábola Editorial, 2012.

SANTOS, Wildson Luiz Pereira dos; MORTIMER, Eduardo Fleucy. Tomada de decisão para a ação social responsável no ensino de ciências. 2001. Disponível em: https://www.scielo.br/pdf/ciedu/v7n1/07.pdf. Acesso em 03 mai. 2020.

SOARES, Magda. Letramento: um tema em três gêneros. Belo Horizonte: Autêntica, 2000.

SOUZA, Josemir da Paixão de. Uma introdução dos livros paradidáticos no ensino de matemática. VI Congresso Internacional de Ensino a matemática. ULBRA, Canoas Rio Grande do Sul, Out. 2013. Disponível em: http://www.conferencias.ulbra.br/index.php/ciem/vi/paper/viewFile/826/320. Acesso em: 12 jun. 2020.

SPALDING, Marcelo. Os cem menores contos brasileiros do século e a reinvenção do miniconto na literatura brasileira contemporânea. Dissertação (Mestrado em Literatura Brasileira, Portuguesa e Luso-africanas) - Instituto de Letras, Universidade

Recebido em: 04/07/2020

Aceito em: $1 \% / 12 / 2020$ 
Federal do Rio Grande do Sul. Porto Alegre, 2008. Disponível em: http://www.marcelospalding.com/arquivos/dissertacao.pdf. Acesso em 11 jun. 2020.

STREET, Brian V. Literacy and Multimodality: STIS Lecture: Inter-Disciplinary Seminars O Laboratório SEMIOTEC, da FALE/UFMG Faculdade de Letras, Belo Horizonte, Brasil, March 9, 2012.

STUMPENHORST, Josh. A nova revolução do professor: práticas pedagógicas para uma nova geração de alunos. Petrópolis, RJ: Vozes, 2018.

VALE, José Misael Ferreira do. Educação Científica e Sociedade. In: (Ed.). Questões atuais para o ensino de Ciências. São Paulo: Escrituras, 1998.

VALE, Ricardo. Como cultivar fungos em sua casa. 2020. (1m36s). Disponível em: https://www.youtube.com/watch?v=S0qroPwgFNo. Acesso em: 12 jun.2020.

VALE, Ricardo. Miniconto- Aluna Bárbara Rodrigues Oliveira- 7 B- Colégio Unifemm 2020.2020 .2 (11s). https://www.youtube.com/watch?v=CLFur68s4Ls. Acesso em: 12 jun. 2020.

VALE, Ricardo. Miniconto- Aluno André Carvalho Medlen de Farias- 7 ano AColégio Unifemm (2020). $2020 . \quad$ (15s). Disponível em: https://www.youtube.com/watch?v=PQ9P5Gk80_E. Acesso em: 12 jun. 2020.

VALE, Ricardo. Miniconto- Aluno Otávio- 7 B- Colégio Unifemm 2020. Disponível em: https://www.youtube.com/watch?v=w0qq_28yAAM. Acesso em: 26 jun. 2020.

VALE, Ricardo. Miniconto- Aluna Flávia Helena Ferreira- 7 ano B Colégio Unifemm 2020. Disponível em: https://www.youtube.com/watch? $\mathrm{v}=\mathrm{PZpYJER} 2 \mathrm{Dlg} \&$ feature=youtu.be. Acesso em: 26 jun. 2020.

VARELA, Paulo. Aprender ciências por investigação na educação pré-escolar: exploração de uma proposta didática em contexto de formação inicial de educadores. Revista Insignare Scientia - RIS, v. 3, n. 1, p. 357-375, 2020.

VERMELHO, Alane Beatriz. Dudu e o professor Aspergilo. Rio de Janeiro: Editora Vieira \& Lent, 2010. 